\title{
Metastatic Spine Tumor Epidemiology: Comparison of Trends in Surgery Across Two Decades and Three Continents
}

\author{
Ernest Wright ${ }^{1}$, Federico Ricciardi ${ }^{2}$, Mark Arts ${ }^{3}$, Jacob M. Buchowski ${ }^{4}$, Chun Kee Chung ${ }^{5}$, Maarten Coppes ${ }^{6}$, \\ Alan Crockard ${ }^{7}$, Bart Depreitere ${ }^{7}$, Michael Fehlings ${ }^{8}$, Norio Kawahara ${ }^{9}$, Chong Suh Lee ${ }^{10}$, Yee Leung ${ }^{11}$, \\ Antonio Martin-Benlloch ${ }^{12}$, Eric Massicotte ${ }^{8}$, Christian Mazel ${ }^{13}$, Cumhur Oner $^{14}$, Wilco Peul ${ }^{15}$, Nasir Quraishi ${ }^{16}$, \\ Yasuaki Tokuhashi ${ }^{17}$, Katsuro Tomita ${ }^{18}$, Christian Ulbricht $^{19}$, Jorrit-Jan Verlaan ${ }^{14}$, Mike Wang ${ }^{20}$, David Choi $^{1}$
}

BACKGROUND: Indications for surgery for symptomatic spinal metastases have become better defined in recent years, and suitable outcome measures have been established against a changing backdrop of patient characteristics, tumor behavior, and oncologic treatments. Nonetheless, variations still exist in the local management of patients with spinal metastases. In this study, we aimed to review global trends and habits in the surgical treatment of symptomatic spinal metastases, and to examine how these have changed over the last 25 years.

METHODS: In this cohort study of consecutive patients undergoing surgery for symptomatic spinal metastases, data were collected using a secure Internet database from 22 centers across 3 continents. All patients were invited to participate in the study, except those unable or unwilling to give consent.

RESULTS: There was a higher incidence of colonic, liver, and lung carcinoma metastases in Asian countries, and more frequent presentation of breast, prostate, melanoma metastases in the West. Trends in surgical technique were broadly similar across the centers. Overall survival rates after surgery were $53 \%$ at 1 year, $31 \%$ at 2 years, and $10 \%$ at 5 years after surgery (standard error 0.013 for all). Survival improved over successive time periods, with longer survival in patients who underwent surgery in 2011-2016 compared with those who underwent surgery in earlier time periods.

CONCLUSIONS: Surgical habits have been fairly consistent among countries worldwide and over time. However, patient survival has improved in later years, perhaps due to medical advances in the treatment of cancer, improved patient selection, and operating earlier in the course of disease.

\section{INTRODUCTION}

he contemporary spinal surgeon is becoming increasingly aware of spinal tumors; metastases are the most common neoplasms of the spine and will present in greater numbers as the global population ages. ${ }^{I}$ Due to differences in

\section{Key words \\ - Epidemiology \\ Metastases \\ - Spine \\ - Surgery \\ - Tumor}

\section{Abbreviations and Acronyms \\ EQ-5D: EuroQol 5-Dimension \\ GSTSG: Global Spine Tumour Study Group \\ UK: United Kingdom}

From the ${ }^{1}$ Department of Neurosurgery, National Hospital for Neurology and Neurosurgery, University College London, London, United Kingdom; ${ }^{2}$ Department of Statistical Science, University College London, London, United Kingdom; ${ }^{3}$ Department of Neurosurgery, Medical Center Haaglanden, Haaglanden, The Netherlands; ${ }^{4}$ Departments of Orthopedic and Neurological Surgery, Washington University, St. Louis, Missouri, USA; ${ }^{5}$ Department of Neurosurgery, Seoul National University Hospital, Seoul, Republic of Korea; ${ }^{6}$ Department of Neurosurgery, University Medical Center Groningen, Groningen, The Netherlands; ${ }^{7}$ Division of Neurosurgery, University Hospital Leuven, Leuven, Belgium; ${ }^{\boldsymbol{8}}$ Division of Neurosurgery and Spinal Program, University of Toronto and Toronto Western Hospital, Toronto, Ontario,
Canada; ${ }^{\mathbf{9}}$ Department of Orthopedic Surgery, Kanazawa Medical University Hospital, Kanazawa, Japan; ${ }^{10}$ Spine Center, Samsung Medical Center, Seoul, Republic of Korea; ${ }^{11}$ Department of Orthopaedics, Musgrove Park Hospital, Taunton, United Kingdom; ${ }^{12}$ Spinal Unit, University Hospital Dr Peset, Valencia, Spain; ${ }^{13}$ Department of Orthopedic Surgery, Institut Mutualiste Montsouris, Paris, France; ${ }^{14}$ Department of Orthopedic Surgery, University Medical Center Utrecht, Utrecht, The Netherlands; ${ }^{15}$ Department of Neurosurgery, Leiden University Medical Centre, Leiden, The Netherlands; ${ }^{16}$ Centre for Spine Studies and Surgery, Queens Medical Centre, Nottingham, United Kingdom; ${ }^{17}$ Department of Orthopedic Surgery, Nihon University School of Medicine, Japan; ${ }^{18}$ Department of Orthopedic Surgery, Kanazawa University, Kanazawa, Japan; ${ }^{19}$ Department of Neurosurgery, Charing Cross Hospital, London, United Kingdom; and ${ }^{20}$ Department of Neurosurgery, University of Miami Hospital, Miami, Florida, USA

To whom correspondence should be addressed: David Choi, Ph.D.

[E-mail: david.choi@nhs.net]

Citation: World Neurosurg. (2018) 114:e809-e817.

https://doi.org/10.1016/j.wneu.2018.03.091

Journal homepage: Www.WORLDNEUROSURGERY.org

Available online: www.sciencedirect.com

1878-8750/\$ - see front matter ๔ 2018 Elsevier Inc. All rights reserved. 
local management protocols, the decision to undergo surgery and choice of specific operations are likely to vary between geographic regions. Published studies examining spinal metastases are largely limited to the experience of single centers using a variety of tumor classification systems and outcomes measures, making it difficult to compare clinical practices. ${ }^{2-10}$ As a consequence, the differences in regional practices to treat spinal metastases remain poorly documented.

The Global Spinal Tumour Study Group (GSTSG) maintains an international, prospectively collected dataset on the surgical treatment of spinal metastases using a standardized classification system of surgical approaches and the EuroQol 5-Dimension (EQ$5 \mathrm{D})$ health outcome measure to describe functional outcomes. ${ }^{2, \mathrm{II}}$ Here we describe the epidemiologic characteristics, surgical management, and outcomes of spinal metastatic disease in Io countries in 4 different regions of the world to explore variations in surgical trends over time and region.

\section{METHODS}

\section{Inclusion/Exclusion Criteria}

Patients diagnosed with spinal metastases between March I99I and September 2016 at 22 referral centers in ro countries throughout Asia (China, Korea, and Japan), mainland Europe (Belgium, Denmark, France, The Netherlands, and Spain), the United Kingdom, and North America (Canada and the United States) were recruited for entry into the GSTSG database. All patients underwent surgical intervention. Anonymized patient data was entered into the database directly by practitioners. Patients who were unable to provide consent for participation in research or had incomplete follow-up data (date of death or minimum 2year follow-up) were excluded from the database. Ethical regulatory approval was obtained at each of the institutions contributing to the GSTSG database, and all patients gave informed consent.

\section{Variables}

Clinical data collected included primary malignancy type, spinal levels involved, other sites of metastases (both visceral and extraspinal bone metastases), surgical approach, extent of resection performed, surgical details, quality of life at presentation as assessed by EQ-5D, Frankel score, and survival. The extent of resection was stratified according to whether debulking, intralesional corpectomy, or complete vertebrectomy was performed. The STROBE reporting guideline has been implemented in the preparation of this report.

\section{Statistical Analysis}

Descriptive statistical summary measures were used to assess relevant variables. Continuous variables are reported as mean and standard deviation; binary and categorical variables, as frequency and percentage. Kaplan-Meier survival estimators were fitted, and curves were constructed. A P value $<0.05$ was considered significant. Data analyses were performed using Stata version I3 (StataCorp, College Station, Texas USA).

\section{RESULTS}

A total of 2I48 patients with spinal metastases were admitted to the participating referral centers between March I99I and

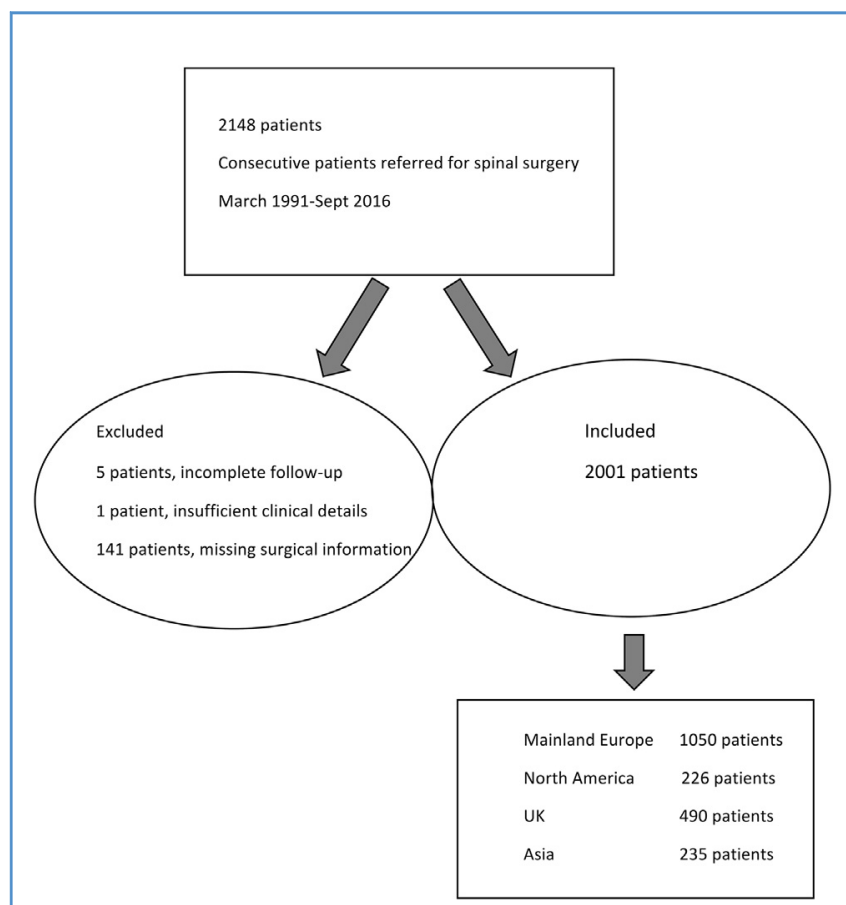

Figure 1. CONSORT flow diagram for patient recruitment and exclusion

September 2016 (Figure 1). After application of exclusion criteria, 200I study participants remained $(93.2 \%)$. The reasons for exclusion were incomplete follow-up in 5 patients (0.2\%), insufficient patient details in I patient, and missing information on surgical approach in I4I patients $(6.6 \%)$. The data were analyzed in 4 regions: the United Kingdom (UK), mainland Europe, North America, and Asia. The UK was considered a separate category from mainland Europe owing to anecdotal differences in surgical approach and management compared with other European centers.

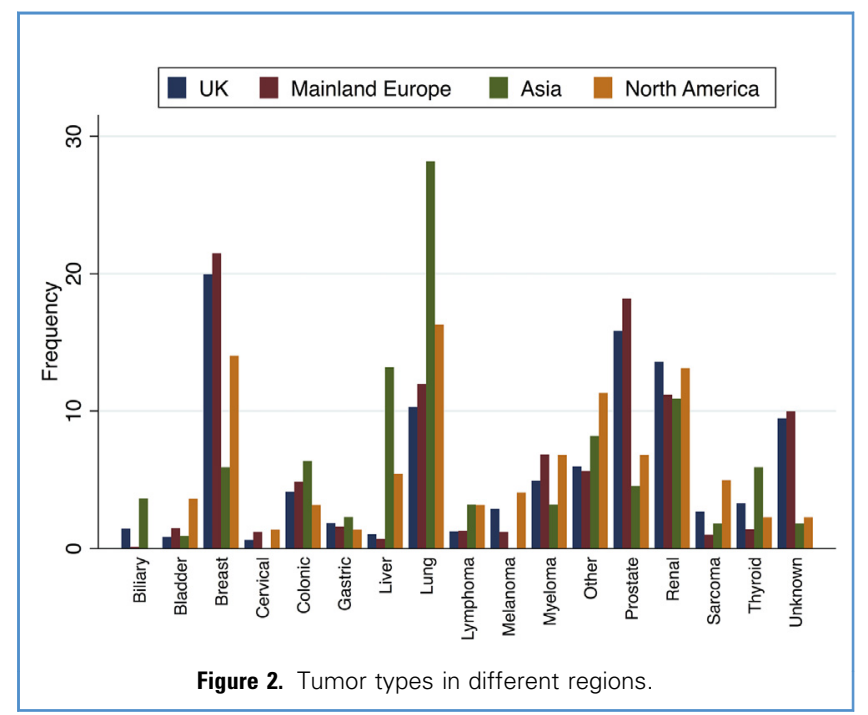




\begin{tabular}{|lccccc|}
\hline Table 1. Tumor Type by Global Region \\
Tumor & $\begin{array}{c}\text { UK, } \\
\text { Number } \\
\text { Type }\end{array}$ & $\begin{array}{c}\text { Mainland } \\
\text { Europe, } \\
\text { Number } \\
(\%)\end{array}$ & $\begin{array}{c}\text { Asia, } \\
\text { Number } \\
(\%)\end{array}$ & $\begin{array}{c}\text { North } \\
\text { America, } \\
\text { Number } \\
(\%)\end{array}$ & $\begin{array}{c}\text { Total, } \\
\text { Number } \\
(\%)\end{array}$ \\
\hline Biliary & $7(1.4)$ & $1(0.1)$ & $8(3.6)$ & $0(0)$ & $16(0.8)$ \\
\hline Bladder & $4(0.8)$ & $15(1.5)$ & $2(0.9)$ & $8(3.6)$ & $29(1.5)$ \\
\hline Breast & $97(20.0)$ & $217(21.5)$ & $13(5.9)$ & $31(14.0)$ & $358(18.5)$ \\
\hline Cervical & $3(0.6)$ & $12(1.2)$ & $0(0)$ & $3(1.4)$ & $18(0.9)$ \\
\hline Colon & $20(4.1)$ & $49(4.9)$ & $14(6.4)$ & $7(3.2)$ & $90(4.6)$ \\
\hline Gastric & $9(1.9)$ & $16(1.6)$ & $5(2.3)$ & $3(1.4)$ & $33(1.7)$ \\
\hline Liver & $5(1.0)$ & $7(0.7)$ & $29(13.2)$ & $12(5.4)$ & $53(2.7)$ \\
\hline Lung & $50(10.3)$ & $121(12.0)$ & $62(28.1)$ & $36(16.3)$ & $269(13.9)$ \\
\hline Lymphoma & $6(1.2)$ & $13(1.3)$ & $7(3.2)$ & $7(3.2)$ & $33(1.7)$ \\
\hline Melanoma & $14(2.9)$ & $12(1.2)$ & $0(0)$ & $9(4.1)$ & $35(1.8)$ \\
\hline Myeloma & $24(4.9)$ & $69(6.8)$ & $7(3.2)$ & $15(6.8)$ & $115(5.9)$ \\
\hline Other & $29(6.0)$ & $57(5.6)$ & $18(8.2)$ & $25(11.3)$ & $129(6.7)$ \\
\hline Prostate & $77(15.8)$ & $184(18.2)$ & $10(4.6)$ & $15(6.8)$ & $286(14.8)$ \\
\hline Renal & $66(13.6)$ & $113(11.2)$ & $24(10.9)$ & $29(13.1)$ & $232(12.0)$ \\
\hline Sarcoma & $13(2.7)$ & $10(1.0)$ & $4(1.8)$ & $11(5.0)$ & $38(2.0)$ \\
\hline Thyroid & $16(3.3)$ & $14(1.4)$ & $13(5.9)$ & $5(2.3)$ & $48(2.5)$ \\
\hline Unknown & $46(9.5)$ & $101(10.0)$ & $4(1.8)$ & $5(2.3)$ & $156(8.1)$ \\
\hline Total & $486(100.0)$ & $1011(100.0)$ & $220(100.0)$ & $221(100.0)$ & $1938(100.0)$ \\
\hline Missing, $n=63(3.2 \%)$ & & & & \\
\hline & & & & & \\
\hline
\end{tabular}

There were substantial differences in the frequency of tumor types reported in Asia compared with other regions (Figure 2). Asian centers diverged from prevailing trends with higher frequencies of colonic, liver, and lung carcinoma metastases and

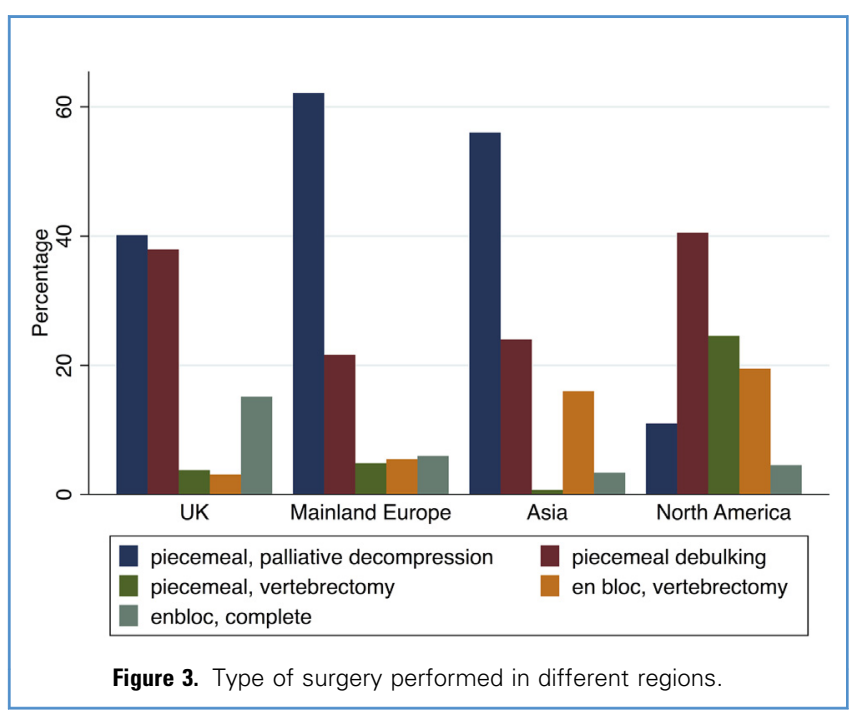

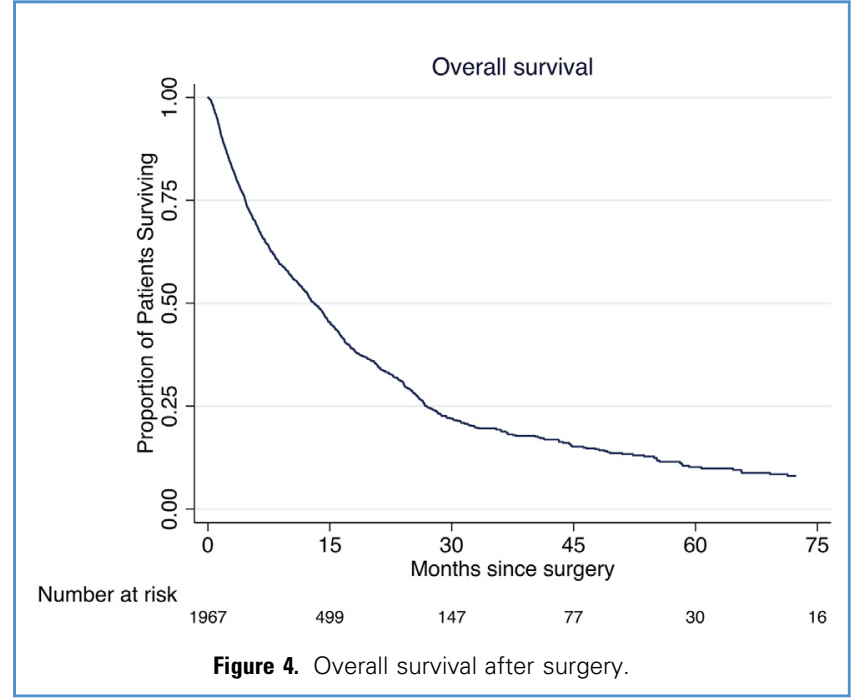

lower frequencies of breast, prostate, and melanoma metastases and myeloma. For example, the reported incidence of liver carcinoma metastases was $13 \%$ in Asian centers, compared with $<5 \%$ in centers outside of Asia. Similarly, lung carcinoma metastases were found in $28 \%$ of Asian referrals, compared with I0\%- $6 \%$ elsewhere. In contrast, Asian centers had markedly lower rates of breast carcinoma metastases compared with the other regions ( $6 \%$ vs. $14 \%-21 \%$ of referrals) and less than one half the rate of myeloma $(3 \%)$ reported in mainland Europe and North America (Table 1).

Comparing the 4 regions revealed a significantly lower incidence of metastatic prostate cancer in Asia (5\%) and North America ( $7 \%$ ) compared with those reported in Europe and the UK (I6\%-18\%). Sarcomas exhibited a unique trend, with higher rates in UK and North America (3\% and 5\% respectively), than in Asia and Europe ( $2 \%$ and $\mathrm{r} \%$, respectively). Rates of lymphoma, renal,

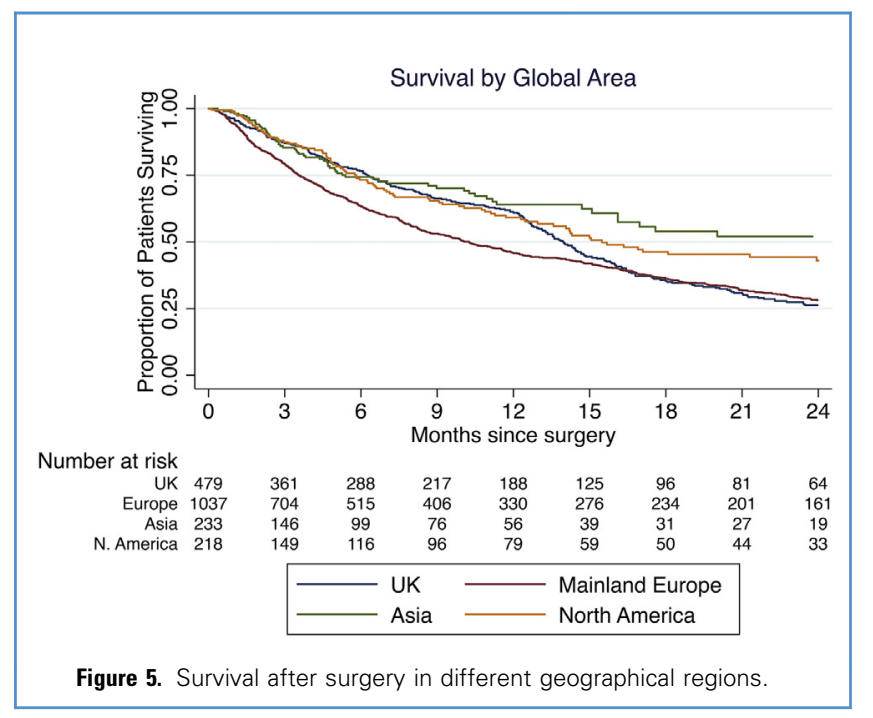




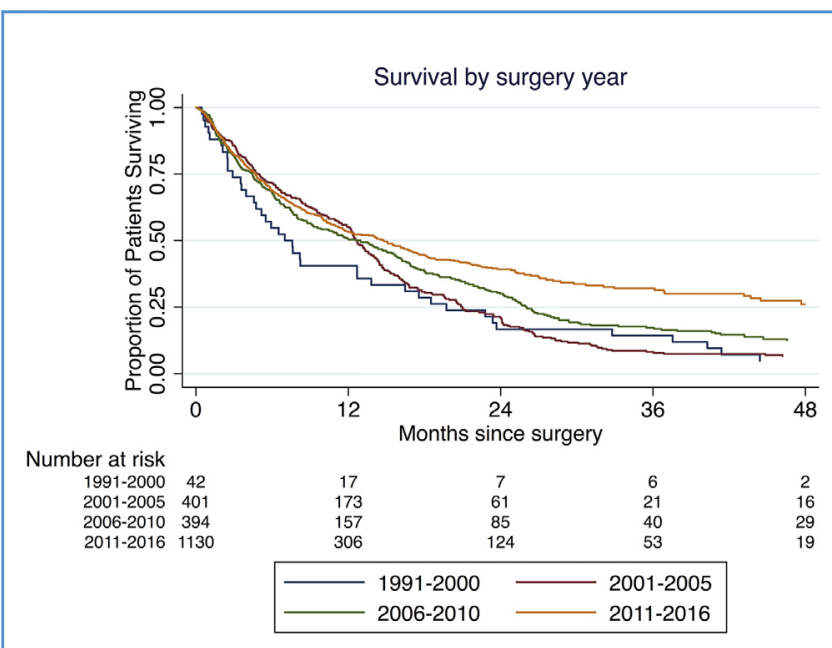

Figure 6. Survival after surgery for successive 5-year recruitment periods, demonstrating improving outcomes.

and other uncategorized metastases were similar across the 4 regions.

Despite the differences in frequency of tumor types across regions, there was little variation in the male:female ratio, with the percentage of male patients ranging from $55 \%$ to $60 \%$ globally (54.9\% in the UK, $57.0 \%$ in mainland Europe, 60.4\% in Asia, and $59.7 \%$ in North America). Similarly, the average age of patients at presentation ranged from 58 to 62 years across all regions (mean age, 6r.6 years in UK, 62.o years in mainland Europe, 6o.o years in Asia, and 58.I years in North America).

Globally, the majority of surgery was performed via a posterioronly midline approach to the spine. Isolated posterior approaches were use in $77 \%$ (in North America) to $94 \%$ of cases (in Asia). Combined anterior-posterior approaches to the spine and anterior-only approaches were the next most common, used less

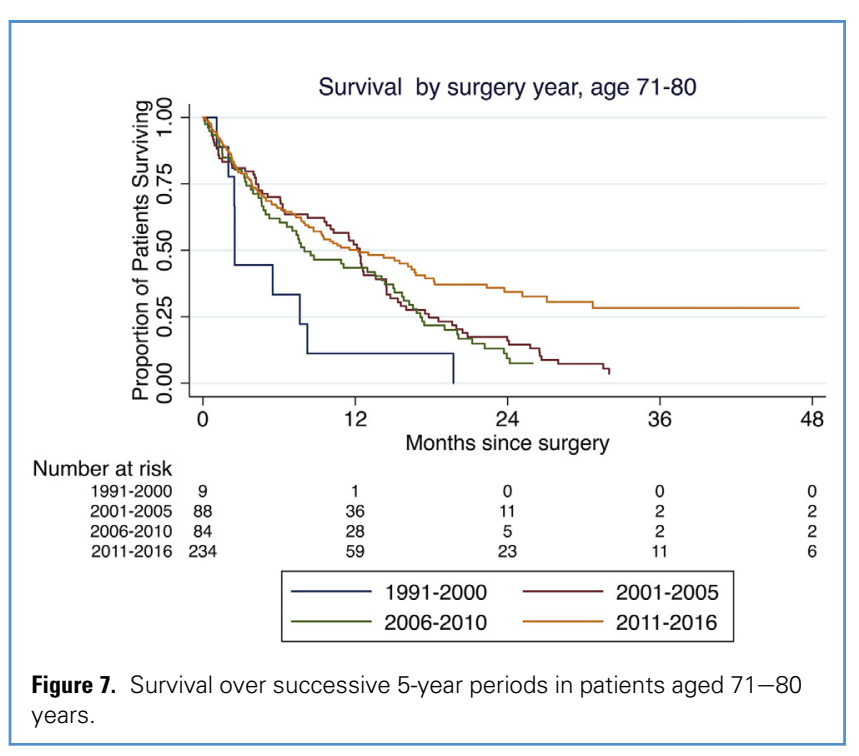

than $20 \%$ and $10 \%$ of the time, respectively. Preoperative endovascular tumor embolization was performed in $10 \%-22 \%$ of cases worldwide, including $9.6 \%$ of cases in the UK, $14.6 \%$ in mainland Europe, $22.1 \%$ in Asia, and $16.4 \%$ in North America.

Trends in the extent of surgical resection differed between North American centers and other regions. In the UK, Europe, and Asia, the majority of cases performed were piecemeal resections with the objective of palliative decompression (defined as $<50 \%$ of tumor resected, as judged by the surgeon at the time of the operation; Figure 3). In contrast palliative decompressions were less frequent in North America; the most commonly performed procedure in North American centers was piecemeal debulking of the metastatic lesion with $>50 \%$ of the lesion resected. In most regions, more palliative and debulking surgeries were performed compared with complete corpectomies or en bloc resections. North American centers departed from this global trend, with a larger proportion of more aggressive resections. In Asian centers, piecemeal vertebrectomy was uncommon; as a result, resections in Asia can be largely dichotomized into piecemeal procedures or en bloc vertebrectomy, revealing a preference for en bloc resection when vertebrectomy was the objective.

The mean case duration differed little between regions, ranging from 3.3 to 3.8 hours globally. The distribution of case duration reveals that most cases were clustered around the overall mean of 3.5 hours in mainland European ( 3.3 hours) and North American (3.6 hours) centers, but UK and Asian centers had a substantial proportion of cases that lasted longer than 6 hours (mean duration, 3.7 and 3.8 hours, respectively).

The mean duration of stay on the spinal surgery ward varied across the regions: UK, $44 \pm 9 \mathrm{I}$ days; mainland Europe, $29 \pm 2 \mathrm{I} 3$ days; Asia, $28 \pm 3$ I days; North America, $12 \pm 28$ days.

Mean preoperative EQ-5D score was significantly higher in North America compared with the 3 other regions, and was similar among those 3 regions (North America, 0.5I; UK, 0.39; mainland Europe, 0.40 ; Asia, 0.4I). Standard deviation was consistent across the regions, ranging from 0.28 in North America to 0.32 in Asia.

\section{Survival Comparisons}

Overall survival rates were $53 \%$ at I year, $3 \mathrm{I} \%$ at 2 years, and $10 \%$ at 5 years (standard error [SE] 0.013 for all) (Figure 4). Two-year survival in the UK and mainland Europe differed from that in Asia and North America ( $\mathrm{P}<\mathrm{0.05}$ ): UK, mean 26\% (SE 3.0); mainland Europe, mean 28\% (SE 2.0); Asia, mean 52\% (SE 5.0); and North America, mean 42\% (SE 4.0) (Figure 5).

Dividing the study participants into 4-year study periods based on year of surgery allowed for an analysis of trends over time (Figure 6). Although I-year survival rates remained largely unchanged, survival rates beyond I year improved in patients diagnosed in the most recent era. Compared with the baseline $199 \mathrm{I}-2000$ group, there was a nonsignificant improvement in survival in the 2006-2010 group $(P=0.16)$, but significant improvements in the 2006-2010 $(\mathrm{P}=0.02)$ and $201 \mathrm{I}-20 \mathrm{I} 6(\mathrm{P}<\mathrm{0.0I})$ groups. This was particularly evident for the most recent group of patients recruited between $201 \mathrm{I}$ and 2016, for which the Kaplan-Meier survival curve diverges from those of previous time periods.

The greatest difference in survival over the years was seen in the elderly population (age $7 \mathrm{I}-80$ years), with better survival in elderly 
Table 2. Frankel Grade by Year

\begin{tabular}{|c|c|c|c|c|c|}
\hline Frankel Grade & 1991-2001, Number (\%) & 2001-2005, Number (\%) & 2006-2010, Number (\%) & 2011-2016, Number (\%) & Total, Number $(\%)$ \\
\hline A & $0(0.0)$ & $4(1.0)$ & $8(2.0)$ & $18(1.6)$ & $30(1.5)$ \\
\hline B & $2(4.7)$ & $9(2.3)$ & $18(4.4)$ & $45(4.0)$ & $74(3.7)$ \\
\hline C & $14(32.6)$ & $102(25.6)$ & $81(20.0)$ & $220(19.3)$ & $417(21.0)$ \\
\hline D & $16(37.2)$ & $150(37.7)$ & $144(35.5)$ & $348(30.5)$ & $658(33.1)$ \\
\hline $\mathrm{E}$ & $11(25.6)$ & $133(33.4)$ & $155(38.2)$ & $509(44.7)$ & $808(40.7)$ \\
\hline Total & $43(100.0)$ & $398(100.0)$ & $406(100.0)$ & $1140(100.0)$ & $1987(100.0)$ \\
\hline
\end{tabular}

patients with metastatic disease in recent years (Figure 7). Cox regression models of multiple variables revealed improved survival was related to the age at the time of surgery $(P=0.004)$ and the method of surgical tumor excision. Debulking and palliative surgeries were more frequently performed in recent years, and fewer en bloc excisional surgeries are now seen as surgical philosophy has evolved from curative intent to improving quality of life (palliative surgical technique, $\mathrm{P}<\mathrm{o.oI}$ ).

The patients' neurologic status at presentation as indicated by Frankel grade improved over time, with a larger proportion of patients graded as Frankel $\mathrm{E}$ and a concomitant decrease in the proportion of Frankel grade $\mathrm{C}$ and $\mathrm{D}$ patients (Table 2). In the 20II-20I6 group, $44.7 \%$ of patients presented with Frankel grade E, compared with only $25.6 \%$ of patients in the I99I-200I group.

The mean patient age at the time of diagnosis varied little across time periods, averaging between 59.6 and 6r.o years. The extent of resection varied minimally over time, with decompression or simple debulking representing the majority of cases $(71.8 \%-100 \%)$ and complete vertebrectomy the objective in only a minority of cases (I.0\%-I6\%; Table 3). Consistency was also observed in the relative proportions of primary tumor types over time; the 3 most common tumors reported across all time blocks were breast, renal, and lung carcinoma metastases, excluding cases in which there was no known histopathology (Table 4). Analyzing individual tumor types, there was a trend toward better survival in recent years for breast carcinoma metastases $(P=0.18$; Figure 8) and colorectal carcinoma metastases $(P=0.13$; Figure 9$)$, but these trends were not statistically significant, perhaps due to the small sample size. However, there was a significant improvement in survival after surgery for lung cancer $(P=0.04$; Figure 10). Other tumor types were not associated with improved survival in recent years.

\section{DISCUSSION}

Regional Differences in Frequency of Tumor Types

In this study, the first global comparison of the surgical treatment of spinal metastases, we report wide variation in the frequency of metastatic tumor types across regions. The asymmetries observed in different parts of the world largely reflect those of primary cancer diagnoses in the respective regions. For example, the higher rates of gastrointestinal, liver, and lung carcinoma metastases in Asian centers reflects the high frequency of these primary cancers reported in Asia. Examining regional variations in the incidence of liver cancer in particular, China alone accounts for $50 \%$ of the $>750,000$ new diagnoses annually worldwide. ${ }^{\mathrm{I} 2}$ Compared with other regions, the incidence of liver cancer in China is more than 3 times that in North America and Io times that in some European countries. ${ }^{\text {I2 }}$ The relatively small proportion of breast cancer metastases reported in Asian centers

Table 3. Extent of Excision by Year

\begin{tabular}{|c|c|c|c|c|c|}
\hline Extent of Incision & 1991-2000, Number (\%) & 2001-2005, Number (\%) & 2006-2010, Number (\%) & 2011-2016, Number (\%) & Total, Number $(\%)$ \\
\hline Cementoplasty & $0(0.0)$ & $0(0.0)$ & $8(2.0)$ & $26(2.7)$ & $34(1.9)$ \\
\hline Palliative decompression & $43(100.0)$ & $233(58.4)$ & $182(46.3)$ & $435(44.5)$ & $893(49.3)$ \\
\hline Palliative debulking & $0(0.0)$ & $84(21.1)$ & $100(25.5)$ & $316(32.3)$ & $500(27.6)$ \\
\hline Piecemeal vertebrectomy & $0(0.0)$ & $5(1.3)$ & $47(12.0)$ & $62(6.4)$ & $114(6.3)$ \\
\hline En bloc intralesional & $0(0.0)$ & $12(3.0)$ & $35(8.9)$ & $83(8.5)$ & $130(7.2)$ \\
\hline En bloc extralesional & $0(0.0)$ & 65 (16.3) & $21(5.3)$ & $55(5.6)$ & $141(7.8)$ \\
\hline Total & $43(100.0)$ & $399(100.0)$ & $393(100.0)$ & $977(100.0)$ & $1812(100.0)$ \\
\hline
\end{tabular}


Table 4. Comparison of the Presenting Tumor Types in Different Time Periods

\begin{tabular}{|c|c|c|c|c|c|}
\hline Tumor Type & 1991-2000, Number (\%) & 2001-2005, Number (\%) & 2006-2010, Number (\%) & 2011-2016, Number (\%) & Total, Number (\%) \\
\hline Biliary & $0(0.0)$ & $6(1.5)$ & $0(0.0)$ & $10(0.9)$ & $16(0.8)$ \\
\hline Bladder & $0(0.0)$ & $6(1.5)$ & $4(1.0)$ & $19(1.7)$ & $29(1.5)$ \\
\hline Breast & $13(30.2)$ & $91(22.8)$ & $61(15.3)$ & $193(17.6)$ & $358(18.5)$ \\
\hline Cervical & $1(2.3)$ & $3(0.8)$ & $2(0.5)$ & $12(1.1)$ & $18(0.9)$ \\
\hline Colon & $2(4.7)$ & $25(6.3)$ & $19(4.8)$ & $44(4.0)$ & $90(4.6)$ \\
\hline Gastric & $0(0.0)$ & $5(1.3)$ & $4(1.0)$ & $24(2.2)$ & $33(1.7)$ \\
\hline Liver & $0(0.0)$ & $6(1.5)$ & $6(1.5)$ & $41(3.7)$ & $53(2.7)$ \\
\hline Lung & $4(9.3)$ & $54(13.5)$ & 55 (13.8) & $156(14.2)$ & $269(13.9)$ \\
\hline Lymphoma & $0(0.0)$ & $0(0.0)$ & $6(1.5)$ & $27(2.5)$ & $33(1.7)$ \\
\hline Melanoma & $0(0.0)$ & $7(1.8)$ & $7(1.8)$ & $21(1.9)$ & $35(1.8)$ \\
\hline Myeloma & $1(2.3)$ & $1(0.3)$ & $35(8.8)$ & $78(7.1)$ & $115(5.9)$ \\
\hline Other & $1(2.3)$ & $17(4.3)$ & $26(6.5)$ & $85(7.8)$ & $129(6.7)$ \\
\hline Prostate & $8(18.6)$ & $68(17.0)$ & 70 (17.6) & $140(12.8)$ & $286(14.8)$ \\
\hline Renal & $6(14.0)$ & $52(13.0)$ & 48 (12.1) & $126(11.5)$ & $232(12.0)$ \\
\hline Sarcoma & $0(0.0)$ & $1(0.3)$ & $7(1.8)$ & $30(2.7)$ & $38(2.0)$ \\
\hline Thyroid & $2(4.7)$ & $12(3.0)$ & $13(3.3)$ & $21(1.9)$ & $48(2.5)$ \\
\hline Unknown & $5(11.6)$ & $46(11.5)$ & $35(8.8)$ & $70(6.4)$ & 156 (8.1) \\
\hline Total & $43(100.0)$ & $400(100.0)$ & $398(100.0)$ & $1097(100.0)$ & $1938(100.0)$ \\
\hline
\end{tabular}

provides further support for this explanation, as epidemiologic data show that the incidence of breast cancer in the United States is a multiple of that reported in most Asian countries. ${ }^{\mathrm{I2}}$

This explanation fails to account for certain regional variations seen in our study, however. Although Asian centers report the single largest proportion of spinal metastases in any region, with lung cancer accounting for $>25 \%$ of all spinal metastases, the incidence of primary lung cancer diagnoses is actually lower in China compared with the United States. ${ }^{\mathrm{I}, \mathrm{I} 4}$ This unexpected finding may be due in part to early detection initiatives in the United States that call for regular radiographic screening of high-risk patients, resulting in diagnosis of asymptomatic patients with isolated lung nodules before metastasis to distant sites can occur. ${ }^{15-17}$ Also of note is the fact that this study group represents only a subset of patients with spinal metastases, being limited to those who have undergone surgery for treatment of metastatic disease. Consequently, the widespread availability of targeted therapies for lung cancer in the United States may be resulting in better medical control and fewer surgical referrals. ${ }^{18}$ Taken together, these considerations illustrate that there is no simple or straightforward explanation for the different rates of primary tumors metastasizing to the spine. Rather, the interplay among such factors as regional primary cancer rates, cancer screening protocols enabling early detection before distant spread, and access to advanced oncologic therapies likely contributes to producing the regional variations we report here.
Survival Analysis

Examining the results of our survival analysis with respect to the year of diagnosis reveals that long-term survival improved over the time course of this study. Despite the fact that I-year survival

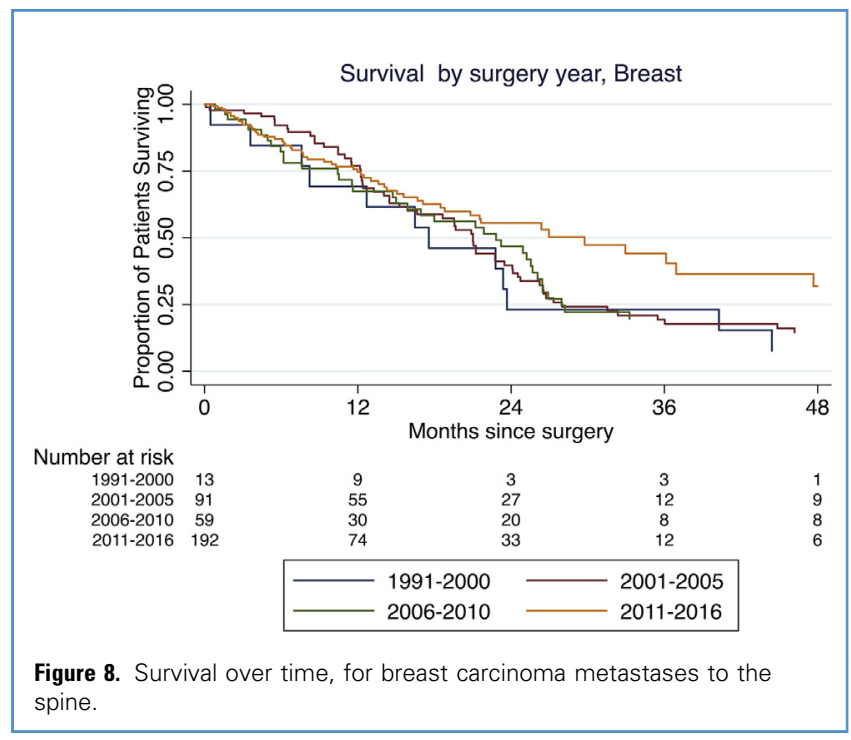




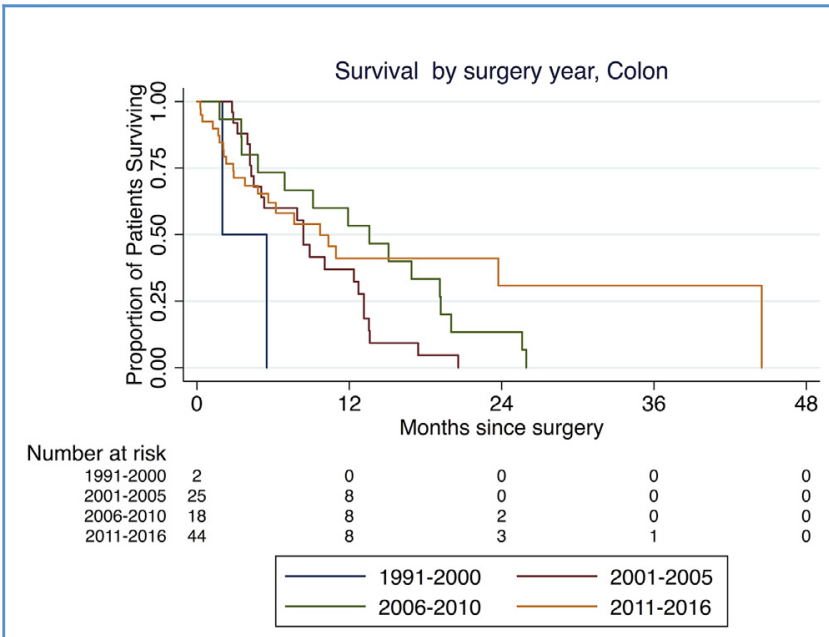

Figure 9. Survival over time, for colorectal carcinoma metastases to the spine.

remained largely unchanged from I99I to 2016, the Kaplan-Meier survival curve for the most recent quartile (20II-20I6) diverged significantly from those representing earlier time periods. The reasons behind this improvement in long-term survival are difficult to determine with certainty, but the fact that the surgical approaches used and the extent of resection achieved did not change throughout the time periods analyzed suggests that the improvements reported here are not attributable to differences in surgical treatment. Rather, it is more likely that the gains achieved in long-term survival reflect a combination of earlier detection, ${ }^{15,16}$ more efficacious adjuvant medical therapies, ${ }^{19-22}$ and a better understanding of spinal metastatic disease leading to selection of patients better suited for surgery with a greater potential for long-term survival. ${ }^{\text {Io }}$ Changes in the medical management of lung cancer are likely to be responsible for better survival in recent years (Figure 10), and similar trends were seen in patients with spinal metastases due to breast or colorectal carcinomas (Figures 8 and 9). The improved survival in more elderly groups may be due to a combination of better medical treatments and more palliative, less extensive (and thus less complicated) surgeries performed in recent years.

\section{EQ-5D}

North American centers reported significantly higher preoperative EQ-5D scores compared with centers in the other 3 regions. This finding could be interpreted as evidence of earlier detection, more timely referrals, or a preference for surgical treatment. Alternatively, this might not reflect a genuine functional difference but instead may be attributed to recognized differences in how patients from different regions self-assess well-being. The purpose of country-specific preference weights as applied to the EQ- $5 \mathrm{D}$ scoring system is to account for known differences in selfassessment and to normalize these differences to facilitate accurate cross-cultural comparisons. In an examination of US, UK, and Japanese EQ-5D country-specific preference weights as applied to a population of Thai patients with type 2 diabetes, Sakthong

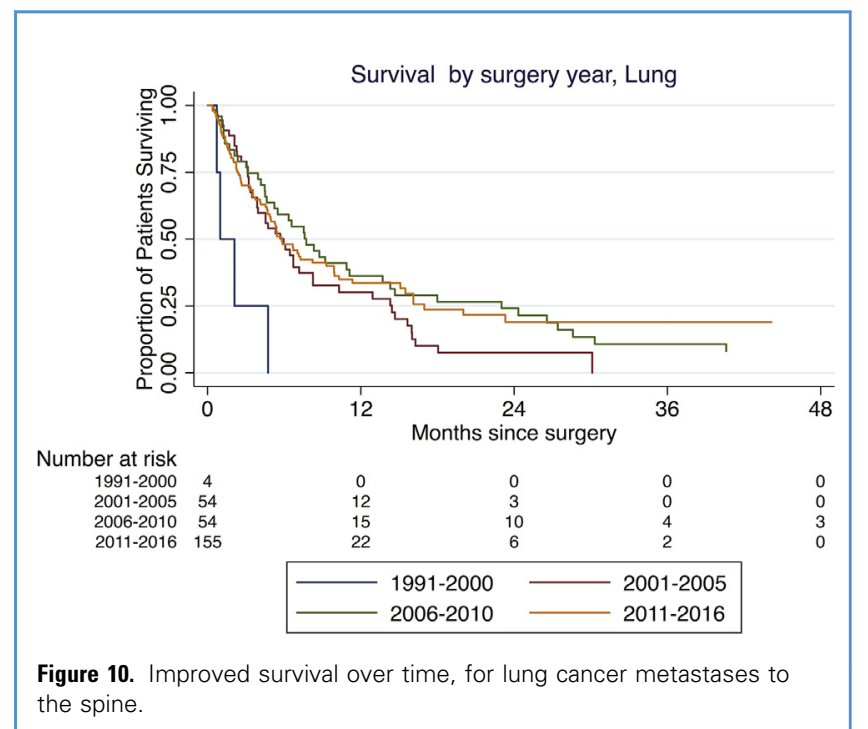

et al. $^{23}$ found that applying the US preference weights yielded higher scores than applying the UK or Japanese preference weights. Whether the higher preoperative $\mathrm{EQ}-5 \mathrm{D}$ scores in US patients reported here is artefactual or attributable to genuine differences in practice is difficult to say.

\section{Limitations}

Our database is subject to inherent limitations that may impact the generalizability of our conclusions. Given that our dataset is composed exclusively of surgical patients, all non-surgically treated patients were excluded from our analyses. Patients with poor prognoses are typically not considered candidates for surgery, and so a focused analysis of surgically treated patients may introduce a selection bias whereby study participants represent a subset of patients with better prognosis than the population of patients with spinal metastases at large. The data in this study were entirely self-reported, and as such are susceptible to reporting bias. This is particularly true for the extent of resection, which was based on each individual surgeon's estimation of the overall percentage of the lesion resected rather than on objective radiologic criteria. Surgical practices may vary across centers, and inclusion of data from units with a preference for more complete or aggressive surgery may bias the results. Finally, the prospective collection of data over the span of more than a decade means that data were collected at different time points.

\section{CONCLUSIONS}

In this first global comparison of the epidemiology, surgical approaches, and long-term survival in patients undergoing surgery for treatment of spinal metastases, we have found substantial regional variation in the composition of primary tumor types leading to spinal metastatic disease despite uniformity in the preferred surgical approach, surgical objectives, and long-term survival. The regional variation reported here should lend further support to the need for global collaboration, given that what is considered a rare metastasis for some may be commonplace for 
others. On a local scale, these data should prompt surgeons to seek out oncologists with specific expertise in managing the metastases that occur most frequently in their region.

The long-term survival data reported here show that patients with spinal metastases are living longer. This improvement in long-term survival should prompt reconsideration of our surgical decision making processes. Many of the prognostic scoring algorithms now used in patient selection for surgery were constructed on data gathered more than a decade ago. Given the improved long-term survival reported for 20II-20I5, surgeons should be wary of using these older prognostic scoring systems, which might exclude patients from surgery on the basis of predictions calculated using old data.
Surgery for spinal metastases can improve pain, deformity, and neurologic function. ${ }^{24}$ It is well recognized that the multidisciplinary team approach is optimal for formulating treatment strategies that yield the best outcomes for patients. Patients with spinal metastases are now living longer without any change in surgical management, suggesting that this enhanced survival is due largely to advances in medical therapy and radiation techniques. Consequently, the survival benefit reported here should be interpreted as providing further support for a collaborative approach to the management of spinal metastases relying on expertise in oncology, surgery, and radiotherapy, to offer an integrated and personalized treatment for patients.

\section{REFERENCES}

I. Godersky JC, Smoker WR, Knutzon R. Use of magnetic resonance imaging in the evaluation of metastatic spinal disease. Neurosurgery. I987;2I: 676-68o.

2. Tomita K, Kawahara N, Kobayashi T, Yoshida A, Murakami H, Akamara T. Surgical strategy for spinal metastases. Spine (Phila Pa 1976). 2001;26: 298-306.

3. North RB, LaRocca VR, Schwartz J, North CA, Zahurak M, Davis RF, et al. Surgical management of spinal metastases: analysis of prognostic factors during a Io-year experience. J Neurosurg Spine. 2005;2:564-573.

4. Gerszten PC, Burton SA, Ozhasoglu C, Welch WC. Radiosurgery for spinal metastases: clinical experience in 500 cases from a single institution. Spine (Phila Pa 1976). 2007;32:193-I99.

5. Tokuhashi Y, Matsuzaki H, Oda H, Oshima M, Ryu J. A revised scoring system for preoperative evaluation of metastatic spine tumor prognosis. Spine (Phila Pa 1976). 2005;30:2I86-2I9I.

6. Hirabayashi H, Ebara S, Kinoshita T, Yuzawa Y, Nakamura I, Takahashi J, et al. Clinical outcome and survival after palliative surgery for spinal metastases: palliative surgery in spinal metastases. Cancer. 2003;97:476-484

7. Jansson KÅ, Bauer HC. Survival, complications and outcome in 282 patients operated for neurological deficit due to thoracic or lumbar spinal metastases. Eur Spine J. 2006;15:196-202.

8. Bauer HC, Wedin R. Survival after surgery for spinal and extremity metastases: prognostication in 24I patients. Acta Orthop Scand. I995;66:I43-I46.

9. Wise JJ, Fischgrund JS, Herkowitz HN, Montgomery D, Kurz LT. Complication, survival rates, and risk factors of surgery for metastatic disease of the spine. Spine (Phila Pa 1976). I999;24: I943-I95I.

Io. Wang MY, Parr AM. An international initiative to define the role for surgery for spinal metastases: the GSTSG. World Neurosurg. 2010;73:426-427.
II. Choi D, Morris S, Crockard A, Albert T, Bunger C, Fehlings M, et al. Assessment of quality of life after surgery for spinal metastases: position statement of the Global Spine Tumour Study Group. World Neurosurg. 2013;80:eI75-eI79.

I2. American Cancer Society. Global Cancer Facts \& Figures, 3rd Edition. Atlanta, GA: American Cancer Society; 2015.

I3. Youlden DR, Cramb SM, Baade PD. The International Epidemiology of Lung Cancer: geographical distribution and secular trends. J Thorac Oncol. 2008;3:8I9-83I.

I4. Gibberd R. Globocan I: Cancer Incidence and Mortality Worldwide. J. Ferlay, D.M. Parkin, P.Pisani, IARC Press, Lyon, I999. Stat Med. 2000; I9:2713-2717.

I5. Moyer VA. Screening for lung cancer: U.S. Preventive Services Task Force recommendation statement. Ann Intern Med. 20I4;160:330-338.

I6. Pastorino U, Bellomi M, Landoni C, De Fiori E, Arnaldi P, Picchio M, et al. Early lung-cancer detection with spiral CT and positron emission tomography in heavy smokers: 2-year results. Lancet. 2003;362:593-597.

I7. National Lung Screening Trial Research Team. Reduced lung-cancer mortality with low-dose computed tomographic screening. N Engl J Med. 20II;365:395-409.

I8. Rolfo C, Passiglia F, Ostrowski M, Farracho L, Ondøichová T, Dolcan A, et al. Improvement in lung cancer outcomes with targeted therapies: an update for family physicians. J Am Board Fam Med. 20I5;28:I24-I33.

I9. International Early Lung Cancer Action Program Investigators. Survival of patients with stage I lung cancer detected on CT screening. N Engl J Med. 2006;355:1763-1771

20. Smith I, Procter M, Gelber RD, Guillaume S, Feyereislova A, Dowsett M, et al. 2-year follow-up of trastuzumab after adjuvant chemotherapy in HER2-positive breast cancer: a randomised controlled trial. Lancet. 2007;369:29-36.
2I. Early Breast Cancer Trialists' Collaborative Group (EBCTCG). Effects of chemotherapy and hormonal therapy for early breast cancer on recurrence and I5-year survival: an overview of the randomised trials. Lancet. 2005;365:I687-I7I7.

22. Chia SK, Speers CH, D'yachkova Y, Kang A, Malfair-Taylor S, Barnett J, et al. The impact of new chemotherapeutic and hormone agents on survival in a population-based cohort of women with metastatic breast cancer. Cancer. 2007;1IO: 973-979.

23. Sakthong $\mathrm{P}$, Charoenvisuthiwongs $\mathrm{R}$ Shabunthom R. A comparison of EQ-5D index scores using the UK, US, and Japan preference weights in a Thai sample with type 2 diabetes. Health Qual Life Outcomes. 2008;6:7I.

24. Choi D, Fox Z, Albert T, Arts M, Balabaud L, Bunger C, et al. Rapid improvements in pain and quality of life are sustained after surgery for spinal metastases in a large prospective cohort. $\mathrm{Br} J$ Neurosurg. 2016;30:337-344.

Conflict of interest statement: This work was funded by the Global Spine Tumour Study Group, a registered charity of England and Wales, Charity Commission number 1134934, and DePuy Synthes (Johnson \& Johnson). This study was performed in part at University College London Biomedical Research Centre, which receives funding from the National Institute for Health Research, UK. The authors are members of the Global Spine Tumour Study Group. Other funders had no input in any aspect of the study or manuscript preparation. The authors disclose the following: M. Arts: stock or other ownership in Nuvasive, Vexim, Fagron, and Pharmine; consulting or advisory role for Amedica, Zimmer Biomet, Silony, and EIT; research funding from Zimmer Biomet, Amedica, Intrinsics, and EIT; patent, royalties, other intellectual property interests with EIT; J. Buchowski: consulting or advisory role, speakers' bureau, research funding, and travel, accommodations, and expenses from Globus Medical; patent, royalties, other intellectual property interests with Globus Medical, K2M, and Wolters Kluwer Health; M. Fehlings: consulting or advisory role with Pfizer Zimmer Biomet, and InVivo Therapeutics; C. S. Lee, consulting or advisory role with U\&I, Korea; research funding 
from Pfizer Korea; and patent, royalties, and other intellectual property interests with Solco, Korea and U\&I, Korea; E. Massicotte: honoraria and travel, accommodations, and expenses from AO Spine North America; C. Mazel: stock or other ownership for Amplitude; honoraria from DePuy Spine, Medtronic, and Zimmer; consulting or advisory role for Ethicon; speakers' bureau: for DePuy Spine and Medtronic; patents, royalties, or other intellectual property interests with CHD; travel, accommodations, and expenses from DePuy, Medtronic, Zimmer, and Clariance; N. Ouraishi: honoraria from AO Spine, Medtronic, and DePuy Synthes speakers' bureau for AO Spine, Medtronic, and DePuy Synthes; travel, accommodations, and expenses from AO Spine, Medtronic, and DePuy Synthes; J. J. Verlaan: consulting or advisory role with and research funding from DePuy Synthes; M. Wang: stock or other ownership for Innovative Surgical Devices and Spinicity; consulting or advisory role with DePuy Spine, AesculapSpine, Jointax, and $K 2 M$; research funding from Department of Defence; patents, royalties, and other intellectual property interests with Children's Hospital of LA, DePuy Spine, Springer Publishing, and Quality Medical Publishing; D. Choi: research funding from DePuy Synthes. All other authors have nothing to disclose.

Received 25 January 2018; accepted 12 March 2018

Citation: World Neurosurg. (2018) 114:e809-e817.

https://doi.org/10.1016/j. wneu.2018.03.091

Journal homepage: www.WORLDNEUROSURGERY.org Available online: www.sciencedirect.com

1878-8750/\$ - see front matter (C) 2018 Elsevier Inc. All rights reserved. 